\title{
Article \\ Genotype-Phenotype Correlations in 208 Individuals with Coffin-Siris Syndrome
}

\author{
Ashley Vasko ${ }^{1}$, Theodore G. Drivas ${ }^{2,3}$ (1) and Samantha A. Schrier Vergano ${ }^{4,5, *(1)}$ \\ 1 Clinical Research Unit, Children's Hospital of The King's Daughters, Norfolk, VA 23507, USA; \\ ashley.vasko@chkd.org \\ 2 Division of Human Genetics, The Children's Hospital of Philadelphia, Philadelphia, PA 19104, USA; \\ Theodore.drivas@pennmedicine.upenn.edu \\ 3 Department of Genetics, The University of Pennsylvania, Philadelphia, PA 19104, USA \\ 4 Division of Medical Genetics and Metabolism, Children's Hospital of The King's Daughters, \\ Norfolk, VA 23507, USA \\ 5 Department of Pediatrics, Eastern Virginia Medical School, Norfolk, VA 23507, USA \\ * Correspondence: samantha.vergano@chkd.org; Tel.: +1-757-668-9723
}

Citation: Vasko, A.; Drivas, T.G.; Schrier Vergano, S.A. GenotypePhenotype Correlations in 208 Individuals with Coffin-Siris Syndrome. Genes 2021, 12, 937. https://doi.org/10.3390/ genes12060937

Academic Editor: Laura Crisponi

Received: 21 May 2021

Accepted: 15 June 2021

Published: 19 June 2021

Publisher's Note: MDPI stays neutral with regard to jurisdictional claims in published maps and institutional affiliations.

Copyright: (c) 2021 by the authors. Licensee MDPI, Basel, Switzerland. This article is an open access article distributed under the terms and conditions of the Creative Commons Attribution (CC BY) license (https:// creativecommons.org/licenses/by/ $4.0 /)$.

\begin{abstract}
Coffin-Siris syndrome (CSS, MIM 135900) is a multi-system intellectual disability syndrome characterized by classic dysmorphic features, developmental delays, and organ system anomalies. Genes in the BRG1(BRM)-associated factors (BAF, Brahma associated factor) complex have been shown to be causative, including ARID1A, ARID1B, ARID2, DPF2, SMARCA4, SMARCB1, SMARCC2, $S M A R C E 1, S O X 11$, and SOX4. In order to describe more robust genotype-phenotype correlations, we collected data from 208 individuals from the CSS/BAF complex registry with pathogenic variants in seven of these genes. Data were organized into cohorts by affected gene, comparing genotype groups across a number of binary and quantitative phenotypes. We determined that, while numerous phenotypes are seen in individuals with variants in the BAF complex, hypotonia, hypertrichosis, sparse scalp hair, and hypoplasia of the distal phalanx are still some of the most common features. It has been previously proposed that individuals with ARID-related variants are thought to have more learning and developmental struggles, and individuals with SMARC-related variants, while they also have developmental delay, tend to have more severe organ-related complications. SOX-related variants also have developmental differences and organ-related complications but are most associated with neurodevelopmental differences. While these generalizations still overall hold true, we have found that all individuals with BAF-related conditions are at risk of many aspects of the phenotype, and management and surveillance should be broad.
\end{abstract}

Keywords: Coffin-Siris syndrome; genotype-phenotype; BAF complex

\section{Introduction}

Genes in the BAF (Brahma/BRG1-associated factor) complex are essential in chromatin remodeling. Pathogenic variants in this complex have been associated with a number of conditions, including Coffin-Siris syndrome (CSS, MIM 135900, ORPHA:1465), NicolaidesBaraitser syndrome (NCBRS, MIM 601358) and other CSS-like conditions (SOX4) [1,2]. A range of learning and developmental differences, organ-related anomalies, and variable physical and facial features typically characterize BAFopathies, a term that has been proposed in its description. The most well-known among these syndromes is CSS. CSS is a well-described intellectual disability disorder characterized classically by facial features and organ-system anomalies. Historically, CSS was classified upon recognition of typical phenotype changes, hypoplasia of the distal phalanx, hypertrichosis, and sparse scalp hair. Genes in the BAF complex have been shown to be causative, including ARID1A, ARID1B, ARID2, DPF2, SMARCA4, SMARCB1, SMARCC2, SMARCE1, SOX11, and SOX4. Individuals display significant variability in terms of learning and developmental differences, as 
well as cardiac, renal, brain, and skeletal malformations [3]. Some more common physical manifestations include agenesis of the corpus callosum, variable cardiac defects, feeding difficulties, hypotonia, and vision and hearing anomalies.

A number of genotype-phenotype correlations have been conducted in individuals with molecularly confirmed CSS. Work in this field has incorporated genotype-phenotype associations for individuals with pathogenic variants in ARID1A, ARID1B, SMARCA4, SMARCB1, SMARCE1, and SOX11 [3-9]. Current hypotheses suggest that genes in the BAF complex associate with transcription factors that play a role in neurodevelopment $[2,8,10]$. In general, more significant developmental delays and fewer anatomic anomalies have been described in individuals with ARID-related variants, compared to individuals with $S M A R C$-related variants in whom developmental delays are thought to be milder, and more severe organ-related complications are seen. SOX11 has been associated with more neurodevelopmental complications [8]. The exact etiology behind these genotype-phenotype correlations remains unknown. This manuscript aims to incorporate each genotype in a comparative by-gene analysis. This report examines genotype-phenotype correlations in a large cohort of individuals from the CSS/BAF complex registry in an effort to further delineate any differences that may be of use to both families and clinicians caring for these individuals.

\section{Materials and Methods}

\subsection{Study Population and Data Collection}

The CSS/BAF complex registry is an Institutional Review Board-approved study (IRB \#15-03-EX-0058), begun in 2015, which enrolls individuals with a molecularly confirmed diagnosis of a BAF-related condition. The registry is a parent-caregiver completed survey, which also includes the collection of medical records. At the time of this submission, there are 341 participants enrolled in the CSS/BAF-related disorders registry. While most individuals are from the United States, there are registrants from many other countries, including Canada, Australia, the United Kingdom, France, Greece, China, India, and others. The ages of individuals range from infancy to adulthood. Parent-completed surveys and medical records are used to collect clinical data, with information on development, facial features, growth patterns, and medical conditions being examined. Information and secured files are collected via RedCap@ data systems.

Individuals were included in our sample population if there was sufficient data supporting their phenotypes. Only individuals for whom we had a confirmed molecular diagnosis of a BAF-related disorder were reviewed; pertinent and available medical records were also examined to validate and expand the data. Of the 341 patients, 208 were found to have enough data for inclusion in our subsequent analyses. We organized the data into cohorts by affected gene, comparing genotype groups across a number of binary and quantitative phenotypes.

To assess developmental delays in each genotype, we utilized the Denver Developmental Screening Test II (DDST-II). The DDST-II is a screening tool used to assess the progression of children who are at risk of developmental delays. The child's age, in months, is demonstrated by the horizontal axis on the DDST-II. The milestones, of which there are 125 , are demonstrated by the vertical axis on the DDST-II. The DDST-II is utilized by determining the child's chronological age and marking it in the screening tool. Hypothetically, the neurotypical child should have accomplished all milestones to the left of their chronological age. We ran a BAF complex by-gene analysis of five developmental milestones, including walk, sit, first word, roll, and crawl acquisition. We took the age that $50 \%$ of children, demonstrated by the DDST-II, accomplished these five milestones. We compared these ages to the average age each genotype completed each milestone. We then calculated the percent delays to determine how delayed each individual was in completing each milestone. 


\subsection{Statistical Analyses}

Data describing binary phenotypes were visualized in $\mathrm{R}$, displaying the proportion of patients, divided by genotype group, affected by each phenotype. These data were analyzed using the Chi-square test, dividing individuals by genotype and comparing the count of individuals within each group affected by each phenotype. $p$-values for phenotypes with nominally statistically significant differences across genotype groups $(p<0.05)$ are indicated. For each phenotype with nominally statistically significant differences, genotypes with an absolute normalized Pearson residual greater than 2 are indicated with an asterisk. Quantitative traits were also visualized in $\mathrm{R}$, displaying the mean value per genotype group + / - the standard error of the mean. These data were analyzed by ANOVA with Tukey's post hoc test to identify significant differences across genotype groups. Nominally statistically significant $(p<0.05)$ differences between gene groups are indicated. Altogether, 36 independent statistical analyses were performed for a study-wise Bonferroni-adjusted $p$-value significance threshold of 0.0014 .

\section{Results}

\subsection{Results}

\subsubsection{Cohort Description}

We identified 208 individuals in our cohort with molecularly confirmed pathogenic variants along the BAF complex and with sufficient phenotypic information for inclusion in our study. Pathogenic variants within ARID1B $(n=130,63 \%)$ and SMARCA4 $(n=32$, $15 \%$ ) were found to be the most common within our cohort. The remaining $22 \%$ of our CSS patients were found to have variants in the following genes (Table 1): ARID1A $(n=15,7 \%)$, SMARCB1 $(n=14,7 \%)$, ARID2 $(n=8,4 \%)$, SOX11 $(n=5,2 \%)$, and SMARCE1 $(n=4,2 \%)$. Males account for $60 \%(n=125)$ of individuals in our sample population, females account for the additional $40 \%(n=83)$. Across our entire CSS cohort, the four most common phenotypes are as follows: hypertrichosis $(109 / 208,52 \%)$, sparse scalp hair $(98 / 208,47 \%)$, hypotonia $(89 / 208,43 \%)$, and hypoplasia of the distal phalanx $(85 / 208,41 \%)$.

\subsubsection{Phenotype Generalizations}

To determine the frequency of CSS phenotypes within patients affected by pathogenic variants in different BAF complex components, we analyzed 28 classic CSS phenotypes in patients with pathogenic variants in each of the seven BAF complex genes represented in our cohort. The results of these analyses are shown in Table 2. Sparse scalp hair $(8 / 15$, $53 \%)$, hypoplasia of the distal phalanx $(8 / 15,53 \%)$, and strabismus $(8 / 15,53 \%)$ were the most common phenotypes reported in individuals with variants in ARID1A. In the ARID1B population, hypertrichosis $(81 / 130,62 \%)$ was the only phenotype reported in the majority of individuals. Sparse scalp hair $(5 / 8,63 \%)$ and global developmental delay $(4 / 8,50 \%)$ were seen in a majority of ARID2 patients. Hypoplasia of the distal phalanx was seen in the majority of SMARCA4 patients (20/32, 63\%). Cryptorchidism, sparse scalp hair, and hypertrichosis were all seen in $50 \%$ of SMARCB1 patients $(7 / 14,3 / 6$ males for cryptorchidism). The SMARCE1 and SOX11 groups each had five or fewer patients, making it difficult to make any general statements about phenotype frequency in these populations.

\subsubsection{Phenotype Frequency}

To assess for differences in phenotype frequency across different CSS patient groups, the frequency of each phenotype across all genotype groups was compared (Figure 1A). Altogether, five phenotypes were identified with nominally statistically significant differences across CSS genotype groups: fifth digit hypoplasia $\left(p=3.185 \times 10^{-3}\right)$, hypertrichosis $\left(p=1.381 \times 10^{-2}\right)$, kidney malformations $\left(p=1.294 \times 10^{-6}\right)$, microcephaly $\left(p=2.694 \times 10^{-3}\right)$, and macrocephaly $\left(p=3.852 \times 10^{-2}\right)$. It should be noted that some of our genotype groups (notably SOX11 and SMARCE1) are composed of very few patients, making the interpretation of some of these statistical results more difficult for these groups in particular. For kidney malformations, these significant differences were primarily driven 
by the relative overabundance of kidney malformations in individuals with ARID1A (normalized Pearson residual of Chi-square analysis $=2.19$ ), SMARCE1 (residual $=3.44$ ), and SMARCB1 (residual $=3.1$ ) variants, and an underabundance of kidney malformations in individuals with ARID1B (residual $=-2.18$ ) variants (Figure S1). The significant differences in microcephaly were chiefly driven by the overabundance of this phenotype in the SMARCA4 patients (residual = 3.3), and the significant differences in macrocephaly were driven by the corresponding underabundance of this phenotype in the SMARCA4 (relative residual $=-2.08$ ) group (Figure S1). For fifth digit hypoplasia, there is a trend towards the enrichment of the phenotype in SMARCA4 (residual = 1.91) and SMARCE1 (residual $=1.85$ ) patients, and a trend towards underrepresentation of this phenotype in ARID1B (residual $=-1.39$ ) and ARID2 (residual $=-1.26$ ) patients. For the hypertrichosis phenotype, there is a trend towards the enrichment of this phenotype in ARID1B patients (residual $=1.48$ ) compared to all other patient groups.

\subsubsection{Developmental Differences}

Individuals with CSS are known to have a wide range of global developmental differences. To identify patient genotypes with the most significant delays, we ran a BAF complex by-gene analysis of five developmental milestones-walk, sit, first word, roll, and crawl acquisition. We compared the average age, in months, that each genotype met these milestones to the average age demonstrated by the DDST-II. The percent delays were then calculated for each genotype. While all genotypes were delayed in walking, individuals with variants in ARID1A were the most significantly delayed (64\%). Individuals with variants in SMARCB1 were most delayed in acquiring their first word (78\%), rolling (57\%), and sitting (55\%). While all genotypes were delayed in crawling, ARID1A individuals $(44 \%)$ were the most significantly delayed. Oddly enough, individuals with variants in SOX11 were early $(50 \%)$ in meeting their roll milestone. Individuals with variants in SOX11 also met their first word (44\%), sit (10\%), and crawl (10\%), milestones earlier than other genotypes.

\subsubsection{Quantitative Traits}

To more rigorously assess differences in quantitative traits across genotype groups, we compared mean values in age at developmental milestone acquisition and birth length/weight (Figure 1B-D). For roll acquisition, there was a general trend towards patients with SMARCB1 variants having delayed acquisition of this developmental milestone compared to all other gene groups, with significant differences specifically seen between patients with ARID1B variants and those with SMARCB1 variants $\left(p=4.0 \times 10^{-2}\right)$. Similarly, there was a general trend towards patients with SMARCB1 variants having delayed sit acquisition compared to all other genotype groups, with significant differences seen between SMARCB1 patients and ARID1B patients $\left(p=6.0 \times 10^{-4}\right)$, and ARID1A patients $\left(p=3.0 \times 10^{-2}\right)$ and SMARCA4 patients $\left(p=5.0 \times 10^{-2}\right)$. Lastly, patients with ARID2 pathogenic variants were found to have significantly shorter birth lengths compared to almost all other genotype groups (ARID2 vs. ARID1B $p=4.8 \times 10^{-9}$, ARID2 vs. SMARCA4 $p=1.9 \times 10^{-8}$, ARID2 vs. ARID1A $p=4.3 \times 10^{-7}$, ARID2 vs. SMARCB1 $p=5.1 \times 10^{-7}$, ARID2 vs. SOX11 $p=1.5 \times 10^{-3}$ ).

\subsection{Figures, Tables and Schemes}

Figure 1A visualizes 29 classic qualitative phenotypes presented in individuals with variants in the BAF complex. We ran a by-gene analysis to assess the differences in the frequency of these phenotypes across genotypes. The results of this analysis are presented in a bar graph. The bars represent the frequency of each phenotype in each genotype. ARIDrelated variants are indicated on the bar graph in shades of blue, SMARC-related variants are presented in shades of pink, and SOX11 is presented in yellow. Numbers above each bar represent the $p$-values for phenotypes with nominally statistically significant differences. 
Figure 1B-D visualizes seven classic quantitative phenotypes presented in individuals with variants in the BAF complex. We ran a by-gene analysis to assess the differences in the frequency of these phenotypes across genotypes. The results of this analysis are presented in bar graphs. The bars represent the frequency of each phenotype in each genotype. ARIDrelated variants are indicated on the bar graph in shades of blue, SMARC-related variants are presented in shades of pink, and SOX11 is presented in yellow. Numbers above each bar represent the $p$-values for phenotypes with nominally statistically significant differences. Vertical lines above the bars represent the margin of error for each phenotype.

Table 1. CSS/BAF-related disorders registry population.

\begin{tabular}{cc}
\hline Gene & Individuals in the Sample Population \\
\hline ARID2 & $8(4 \%)$ \\
ARID1A & $15(7 \%)$ \\
ARID1B & $130(63 \%)$ \\
SMARCA4 & $32(15 \%)$ \\
SMARCB1 & $14(7 \%)$ \\
SMARCE1 & $4(2 \%)$ \\
SOX11 & $5(2 \%)$ \\
Total & 208 \\
\hline
\end{tabular}

Table 2. Classic phenotype expression in individuals with variants in the BAF complex.

\begin{tabular}{|c|c|c|c|c|c|c|c|c|}
\hline $\begin{array}{c}\text { Genes Sample } \\
\text { Population }\end{array}$ & $\begin{array}{c}\text { ARID1A } \\
(n=15)\end{array}$ & $\begin{array}{l}\text { ARID1B } \\
(n=130)\end{array}$ & $\begin{array}{c}\text { ARID2 } \\
(n=8)\end{array}$ & $\begin{array}{c}\text { SMARCA4 } \\
(n=32)\end{array}$ & $\begin{array}{c}\text { SMARCB1 } \\
(n=14)\end{array}$ & $\begin{array}{c}\text { SMARCE1 } \\
(n=4)\end{array}$ & $\begin{array}{l}\text { SOX11 } \\
(n=5)\end{array}$ & $\begin{array}{l}\text { Total Cohort } \\
\quad(n=208)\end{array}$ \\
\hline Features & $\%$ & $\%$ & $\%$ & $\%$ & $\%$ & $\%$ & $\%$ & $\%$ \\
\hline Hypertrichosis & $5 / 1533 \%$ & $81 / 13062 \%$ & $1 / 813 \%$ & $14 / 3244 \%$ & $7 / 1450 \%$ & $0 / 40 \%$ & $1 / 520 \%$ & $109 / 20852 \%$ \\
\hline Sparse Scalp Hair & $8 / 1553 \%$ & $62 / 13048 \%$ & $5 / 863 \%$ & $10 / 3231 \%$ & $7 / 1450 \%$ & $3 / 475 \%$ & $3 / 560 \%$ & $98 / 20847 \%$ \\
\hline $\begin{array}{l}\text { Hypoplasia of the Distal } \\
\text { Phalanx }\end{array}$ & $8 / 1553 \%$ & $43 / 13033 \%$ & $1 / 813 \%$ & $20 / 3263 \%$ & $6 / 1443 \%$ & $4 / 4100 \%$ & $3 / 560 \%$ & $85 / 20841 \%$ \\
\hline Microcephaly & $2 / 1513 \%$ & $11 / 1308 \%$ & $1 / 813 \%$ & $12 / 3238 \%$ & $4 / 1429 \%$ & $0 / 40 \%$ & $1 / 520 \%$ & $31 / 20815 \%$ \\
\hline Macrocephaly & $1 / 157 \%$ & $31 / 13024 \%$ & $1 / 813 \%$ & $1 / 323 \%$ & $3 / 1421 \%$ & $0 / 40 \%$ & $0 / 50 \%$ & $37 / 20818 \%$ \\
\hline \multicolumn{9}{|l|}{$\begin{array}{l}\text { Genitourinary } \\
\text { Complications }\end{array}$} \\
\hline Cryptochidism (Males) & $3 / 933 \%$ & $36 / 8244 \%$ & $0 / 80 \%$ & $2 / 1118 \%$ & $3 / 650 \%$ & $0 / 40 \%$ & $1 / 520 \%$ & $45 / 12536 \%$ \\
\hline Kidney Anomalies & $5 / 1533 \%$ & $8 / 1306 \%$ & $0 / 80 \%$ & $5 / 3216 \%$ & $2 / 1414 \%$ & $1 / 425 \%$ & $0 / 50 \%$ & $21 / 20810 \%$ \\
\hline \multicolumn{9}{|l|}{$\begin{array}{l}\text { Gastrointestinal } \\
\text { Complications }\end{array}$} \\
\hline GERD & $3 / 1520 \%$ & $22 / 13017 \%$ & $2 / 825 \%$ & $10 / 3231 \%$ & $4 / 1429 \%$ & $2 / 450 \%$ & $0 / 50 \%$ & $43 / 20821 \%$ \\
\hline Chronic Constipation & $3 / 1520 \%$ & $27 / 13021 \%$ & $2 / 825 \%$ & $6 / 3219 \%$ & $2 / 1414 \%$ & $0 / 40 \%$ & $1 / 520 \%$ & $41 / 20820 \%$ \\
\hline \multicolumn{9}{|l|}{ Cardiac } \\
\hline Atrial Septal Defect & $3 / 1520 \%$ & $15 / 13012 \%$ & $0 / 80 \%$ & $1 / 323 \%$ & $2 / 1414 \%$ & $2 / 450 \%$ & $0 / 50 \%$ & $23 / 20811 \%$ \\
\hline \multicolumn{9}{|l|}{ Neurological } \\
\hline Hypotonia & $7 / 1547 \%$ & $57 / 13044 \%$ & $3 / 838 \%$ & $12 / 3238 \%$ & $5 / 1436 \%$ & $3 / 475 \%$ & $2 / 540 \%$ & $89 / 20843 \%$ \\
\hline Seizures & $3 / 1520 \%$ & $17 / 13013 \%$ & $0 / 80 \%$ & $1 / 323 \%$ & $2 / 1414 \%$ & $1 / 425 \%$ & $1 / 520 \%$ & $25 / 20812 \%$ \\
\hline $\begin{array}{l}\text { Global Developmental } \\
\text { Delays }\end{array}$ & $7 / 1547 \%$ & $46 / 13035 \%$ & $4 / 850 \%$ & $13 / 3241 \%$ & $6 / 1443 \%$ & $2 / 450 \%$ & $2 / 540 \%$ & $80 / 20838 \%$ \\
\hline $\begin{array}{l}\text { Agenesis of the Corpus } \\
\text { Callosum }\end{array}$ & $6 / 1540 \%$ & $31 / 13024 \%$ & $1 / 813 \%$ & $8 / 3225 \%$ & $5 / 1436 \%$ & $1 / 425 \%$ & $0 / 50 \%$ & $52 / 20825 \%$ \\
\hline Non-Verbal & $3 / 1520 \%$ & $9 / 1307 \%$ & $0 / 80 \%$ & $3 / 329 \%$ & $1 / 147 \%$ & $0 / 40 \%$ & $0 / 50 \%$ & $16 / 2088 \%$ \\
\hline ASD & $2 / 1513 \%$ & $21 / 13016 \%$ & $0 / 80 \%$ & $0 / 320 \%$ & $2 / 1414 \%$ & $0 / 40 \%$ & $0 / 50 \%$ & $25 / 20812 \%$ \\
\hline Intellectual Disability & $5 / 1533 \%$ & $42 / 13032 \%$ & $1 / 813 \%$ & $4 / 3213 \%$ & $3 / 1421 \%$ & $1 / 425 \%$ & $1 / 520 \%$ & $57 / 208 \mathbf{2 7} \%$ \\
\hline \multicolumn{9}{|l|}{ Spine } \\
\hline Scoliosis & $4 / 1527 \%$ & $19 / 13015 \%$ & $2 / 825 \%$ & $4 / 3213 \%$ & $4 / 1429 \%$ & $1 / 425 \%$ & $1 / 520 \%$ & $35 / 20817 \%$ \\
\hline
\end{tabular}


Table 2. Cont.

\begin{tabular}{|c|c|c|c|c|c|c|c|c|}
\hline $\begin{array}{l}\text { Genes Sample } \\
\text { Population }\end{array}$ & $\begin{array}{l}\text { ARID1A } \\
(n=15)\end{array}$ & $\begin{array}{l}\text { ARID1B } \\
(n=130)\end{array}$ & $\begin{array}{c}\text { ARID2 } \\
(n=8)\end{array}$ & $\begin{array}{l}\text { SMARCA4 } \\
(n=32)\end{array}$ & $\begin{array}{c}\text { SMARCB1 } \\
(n=14)\end{array}$ & $\begin{array}{l}\text { SMARCE1 } \\
\quad(n=4)\end{array}$ & $\begin{array}{l}\text { SOX11 } \\
(n=5)\end{array}$ & $\begin{array}{l}\text { Total Cohort } \\
\quad(n=208)\end{array}$ \\
\hline \multicolumn{9}{|l|}{ Opthamologic } \\
\hline Ptosis & $5 / 1533 \%$ & $17 / 13013 \%$ & $0 / 80 \%$ & $5 / 3216 \%$ & $1 / 147 \%$ & $0 / 40 \%$ & $1 / 520 \%$ & $29 / 20814 \%$ \\
\hline Strabismus & $8 / 1553 \%$ & $40 / 13031 \%$ & $1 / 813 \%$ & $10 / 3231 \%$ & $7 / 1450 \%$ & $0 / 40 \%$ & $1 / 520 \%$ & $67 / 20832 \%$ \\
\hline \multicolumn{9}{|l|}{ Respiratory } \\
\hline $\begin{array}{c}\text { Obstructive Sleep } \\
\text { Apnea }\end{array}$ & $1 / 157 \%$ & $14 / 13011 \%$ & $0 / 80 \%$ & $5 / 3216 \%$ & $1 / 147 \%$ & $0 / 40 \%$ & $0 / 50 \%$ & $21 / 20810 \%$ \\
\hline Tracheomalacia & $1 / 157 \%$ & $21 / 13016 \%$ & $1 / 813 \%$ & $3 / 329 \%$ & $3 / 1421 \%$ & $0 / 40 \%$ & $0 / 50 \%$ & $29 / 20814 \%$ \\
\hline Laryngomalacia & $3 / 1520 \%$ & $14 / 13011 \%$ & $1 / 813 \%$ & $4 / 3213 \%$ & $2 / 1414 \%$ & $0 / 40 \%$ & $0 / 50 \%$ & $24 / 20812 \%$ \\
\hline \multicolumn{9}{|l|}{ Hearing Loss } \\
\hline Sensorineural & $2 / 1513 \%$ & $10 / 1308 \%$ & $1 / 813 \%$ & $4 / 3213 \%$ & $2 / 1414 \%$ & $1 / 425 \%$ & $0 / 50 \%$ & $20 / 20810 \%$ \\
\hline Conductive & $3 / 1520 \%$ & $9 / 1307 \%$ & $0 / 80 \%$ & $4 / 3213 \%$ & $1 / 147 \%$ & $1 / 425 \%$ & $0 / 50 \%$ & $18 / 2089 \%$ \\
\hline Unspecified & $1 / 157 \%$ & $14 / 13011 \%$ & $0 / 80 \%$ & $3 / 329 \%$ & $1 / 147 \%$ & $0 / 40 \%$ & $1 / 520 \%$ & $20 / 20810 \%$ \\
\hline Hearing Loss Total & $6 / 1540 \%$ & $33 / 13025 \%$ & $1 / 813 \%$ & $11 / 3234 \%$ & $4 / 1429 \%$ & $2 / 450 \%$ & $1 / 520 \%$ & $58 / 20828 \%$ \\
\hline \multicolumn{9}{|l|}{$\begin{array}{l}\text { Quantitative } \\
\text { Measurements }\end{array}$} \\
\hline Birth Weight (kg) & $\begin{array}{c}2.94(15 \% \text { ile }) \\
-1.06 \mathrm{SD} \\
\end{array}$ & $\begin{array}{c}3.38 \text { (39\%ile) } \\
-0.29 \text { SD } \\
\end{array}$ & $\begin{array}{c}2.89 \text { (14\%ile) } \\
-1.07 \text { SD } \\
\end{array}$ & $\begin{array}{c}2.98(15 \% \text { ile }) \\
-0.93 \mathrm{SD} \\
\end{array}$ & $\begin{array}{c}2.67 \text { (6\% ile) } \\
-1.43 \mathrm{SD} \\
\end{array}$ & $\begin{array}{c}2.15(1 \% \text { ile }) \\
-2.26 \mathrm{SD}\end{array}$ & $\begin{array}{c}2.28(2 \% \text { ile }) \\
-2.05 \mathrm{SD}\end{array}$ & $\begin{array}{c}2.76(10 \% \text { ile }) \\
-1.28 \text { SD }\end{array}$ \\
\hline Birth Length (cm) & $\begin{array}{l}49.37 \text { (38\%ile) } \\
\quad-0.30 \mathrm{SD} \\
\end{array}$ & $\begin{array}{l}48.55 \text { (27\%ile) } \\
\quad-0.60 \mathrm{SD} \\
\end{array}$ & $\begin{array}{c}32.99(<1 \% \text { ile }) \\
\quad-6.41 \mathrm{SD}\end{array}$ & $\begin{array}{c}49.35 \text { (38\%ile) } \\
\quad-0.30 \mathrm{SD} \\
\end{array}$ & $\begin{array}{l}49.87 \text { (46\%ile) } \\
\quad-0.11 \mathrm{SD} \\
\end{array}$ & $\begin{array}{c}45.72(5 \% \text { ile }) \\
-1.66 \mathrm{SD}\end{array}$ & $\begin{array}{l}48.01(21 \% \text { ile }) \\
\quad-0.80 \mathrm{SD} \\
\end{array}$ & $\begin{array}{c}46.26 \text { (7\% ile) } \\
-1.46 \mathrm{SD} \\
\end{array}$ \\
\hline $\begin{array}{c}\text { Developmental } \\
\text { Milestones }\end{array}$ & $\begin{array}{c}\text { Age }(\% \\
\text { delay) }\end{array}$ & $\begin{array}{l}\text { Age }(\% \\
\text { delay) }\end{array}$ & $\begin{array}{c}\text { Age }(\% \\
\text { delay) }\end{array}$ & $\begin{array}{l}\text { Age }(\% \\
\text { delay) }\end{array}$ & $\begin{array}{c}\text { Age }(\% \\
\text { delay) }\end{array}$ & $\begin{array}{l}\text { Age }(\% \\
\text { delay) }\end{array}$ & $\begin{array}{c}\text { Age }(\% \\
\text { delay) }\end{array}$ & $\begin{array}{c}\text { Age }(\% \\
\text { delay) }\end{array}$ \\
\hline $\begin{array}{l}\text { Age Aquired Roll } \\
\text { (months) }\end{array}$ & $9(33 \%)$ & $8(25 \%)$ & $8(25 \%)$ & $8(25 \%)$ & $14(57 \%)$ & $9(33 \%)$ & $4(-50 \%)$ & $9(33 \%)$ \\
\hline $\begin{array}{l}\text { Age Acquired Sit } \\
\text { (months) }\end{array}$ & $12(25 \%)$ & $11(18 \%)$ & $11(18 \%)$ & $13(31 \%)$ & $20(55 \%)$ & $11(18 \%)$ & $10(10 \%)$ & $13(31 \%)$ \\
\hline $\begin{array}{l}\text { Age Acquired Crawl } \\
\text { (months) }\end{array}$ & $16(44 \%)$ & $14(36 \%)$ & $12(25 \%)$ & $14(36 \%)$ & $15(40 \%)$ & $14(36 \%)$ & $10(10 \%)$ & $14(36 \%)$ \\
\hline $\begin{array}{l}\text { Age Acquired First } \\
\text { Word (months) }\end{array}$ & 30 (63\% & $26(58 \%)$ & $17(35 \%)$ & $25(52 \%)$ & $41(73 \%)$ & $31(65 \%)$ & $16(31 \%)$ & $27(55 \%)$ \\
\hline $\begin{array}{l}\text { Age Acquired Walk } \\
\text { (months) }\end{array}$ & $33(64 \%)$ & $23(48 \%)$ & $24(50 \%)$ & $32(63 \%)$ & $22(21 \%)$ & $27(27 \%)$ & $23(48 \%)$ & $26(54 \%)$ \\
\hline
\end{tabular}

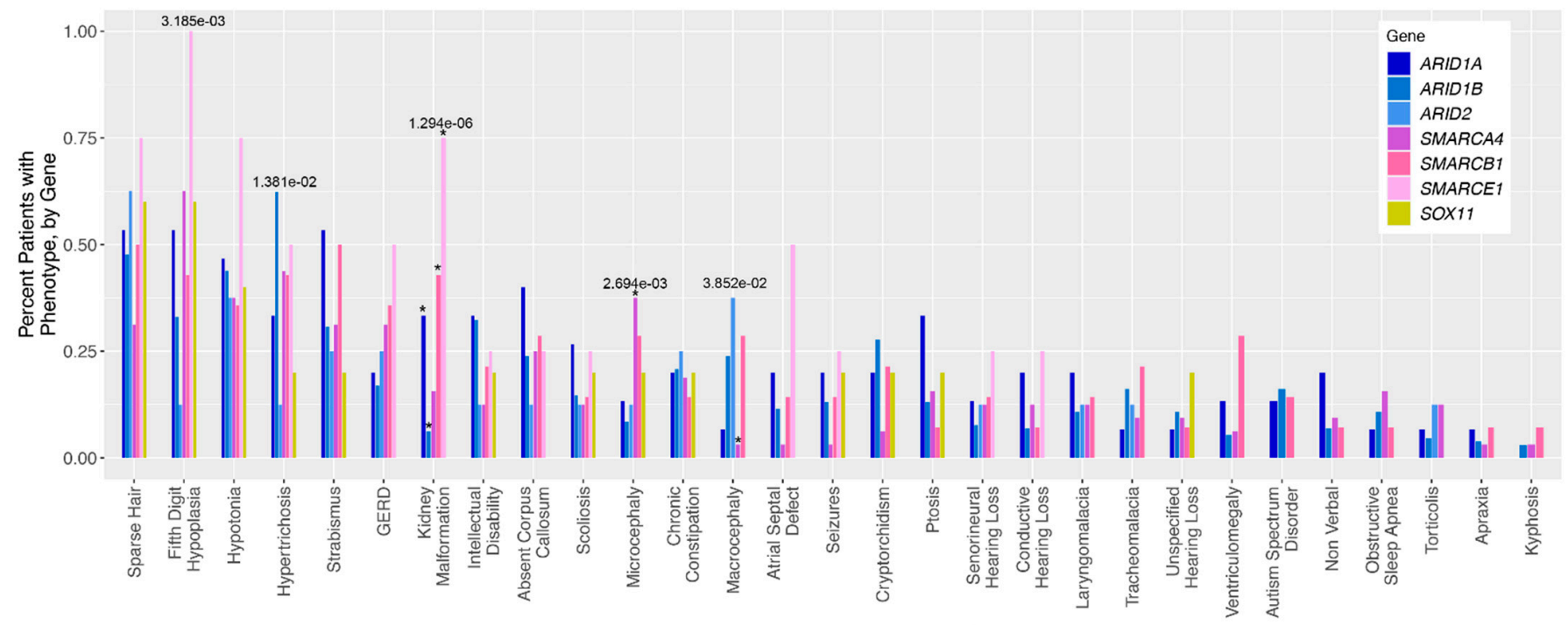

(A)

Figure 1. Cont. 


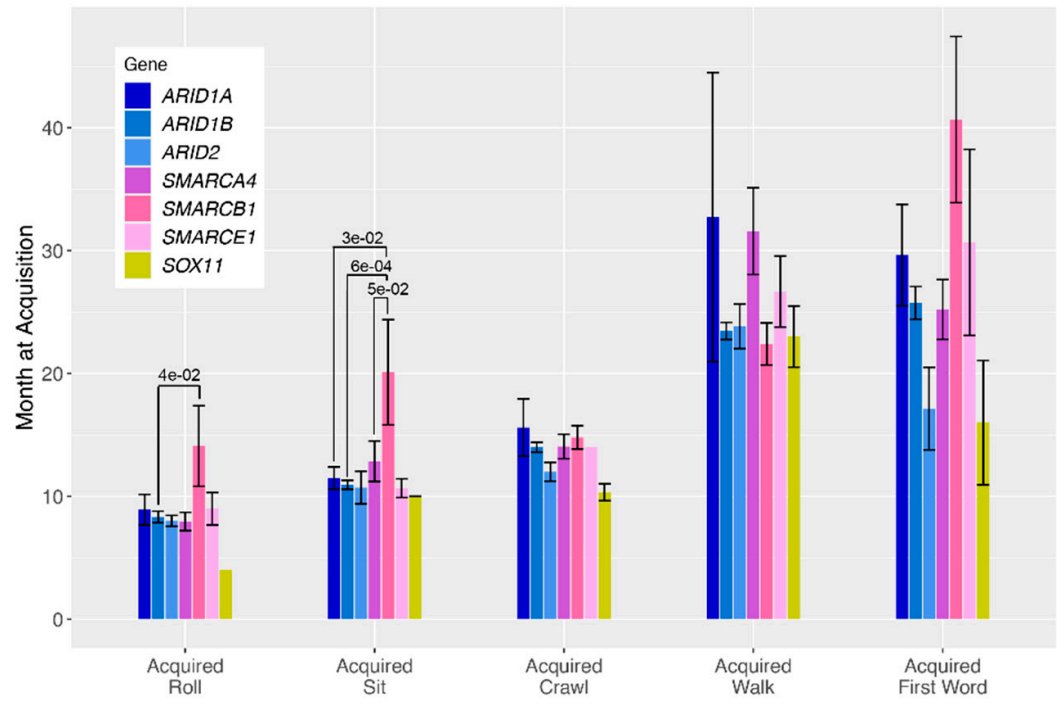

(B)

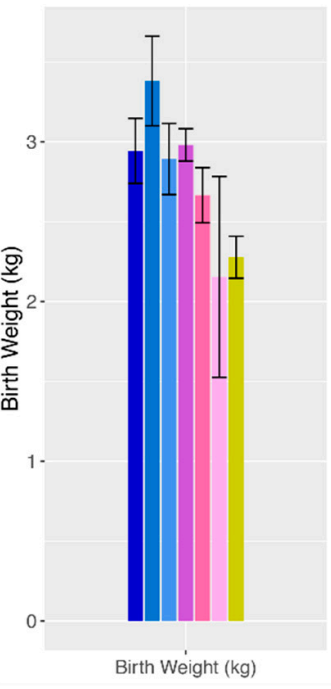

(C)

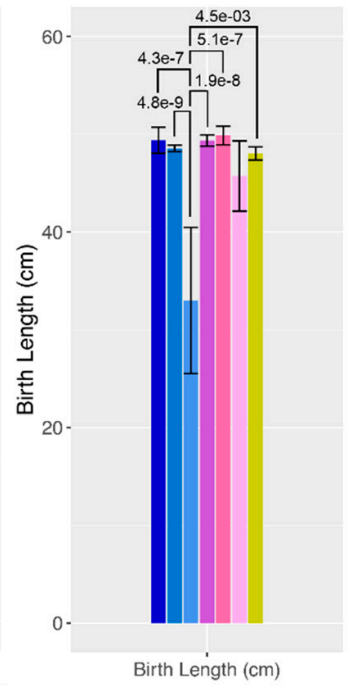

(D)

Figure 1. (A). Qualitative phenotypes in individuals with variants in the BAF complex. (B-D). Quantitative phenotypes in individuals with variants in the BAF complex.

\section{Discussion}

The purpose of this study was to examine genotype-phenotype correlations in a large cohort of individuals from the CSS/BAF-related disorders registry in an effort to identify possible differences across genotype groups. Overall, we found that the phenotypes classically described in CSS, including sparse scalp hair, fifth digit hypoplasia, hypotonia, and hypertrichosis, remained amongst the most common phenotypes reported for all CSS genotype groups. Furthermore, despite previous implications that SMARC and ARIDrelated variants display some degree of phenotypic differentiation, our data revealed largely similar phenotypes across all groups. Only eight phenotypes were identified with nominally statistically significant differences across CSS genotype groups: fifth digit hypoplasia, hypertrichosis, kidney malformations, microcephaly, macrocephaly, age at roll acquisition, age at sit acquisition, and birth length. Of these, only kidney malformations, age at sit acquisition, and birth length can truly be said to be significantly different between genotype groups after correcting for multiple testing. Consistent with what has been previously published, kidney malformations were found to be more common in individuals with SMARCB1 and SMARCE1 variants and underrepresented in individuals with ARID1B variants. Similarly, consistent with previous publications, individuals with SMARCB1 variants were found to have significantly greater developmental delays compared to other groups. Interestingly, the significantly shorter birth length in individuals with ARID2 variants is a finding that has not been previously reported.

There are a number of caveats to our study, with perhaps the greatest being the relatively small number of patients upon which we can base our conclusions. While large numbers of patients with ARID1B $(n=130)$ and SMARCA4 $(n=32)$ were included in our cohort, we could identify only small numbers of individuals with variants in any of the other known CSS genes. Although phenotype correlations were observed within each cohort, it is difficult to make accurate conclusions regarding phenotypic differences in gene groups with limited data, and this must be kept in mind when considering the results of our statistical analyses. Another caveat of our study is its dependence on parent-reported phenotypes and on assessments by different medical providers without a single standard approach to phenotypic description. Individuals' phenotypes are initially inputted by caregivers but ultimately verified with available medical records. While this approach allowed us to ascertain a greater number of CSS patients for inclusion, it also introduces potential bias and noise in the reporting of phenotypes across patients. 


\section{Conclusions}

This manuscript demonstrates that, while there are some genotype-phenotype correlations in variants in the BAF complex, they are not as strong as previously hypothesized. Patients with CSS/BAF-related disorders should still get broad-spectrum genetic testing to distinctly define their BAF-related disorder. The increased risk of neurodevelopmental and organ-related complications should be considered in all individuals with variants in the BAF complex. To prevent and maintain the symptoms of CSS/BAF-related disorders, patients should utilize occupational, physical, and speech therapies. Patients may also benefit from specialty care, such as gastrointestinal, neurology, ophthalmology, nephrology, cardiology, and audiology specialists. The expansion of modern genetic testing and contemporary research may assist families in mitigating these challenges.

Supplementary Materials: The following are available online at https:/ /www.mdpi.com/article/ 10.3390/genes12060937/s1, Figure S1: Adjusted Pearson residuals for five binary phenotypes in individuals with variants in the BAF complex.

Author Contributions: Conceptualization, A.V., T.G.D., and S.A.S.V.; methodology S.A.S.V., and T.G.D.; software, T.G.D.; validation, S.A.S.V., and T.G.D.; formal analysis, T.G.D.; investigation, A.V., T.G.D., and S.A.S.V.; resources, A.V., and S.A.S.V.; data curation, A.V., and S.A.S.V.; writing-original draft preparation, A.V., and S.A.S.V.; writing-review and editing, S.A.S.V., and T.G.D.; visualization, A.V., T.G.D., and S.A.S.V.; supervision, S.A.S.V.; project administration, S.A.S.V. All authors have read and agreed to the published version of the manuscript.

Funding: This research received no external funding.

Institutional Review Board Statement: The study was conducted according to the guidelines of the Declaration of Helsinki, and approved by the Institutional Review Board (or Ethics Committee) of Eastern Virginia Medical School (protocol code 15-03-EX-0058, date of approval 3 May 2015).

Informed Consent Statement: Informed consent was obtained from all subjects involved in the study.

Data Availability Statement: The data presented in this study are available on request from the corresponding author. The data are not publicly available due to IRB restrictions.

Conflicts of Interest: Vergano is a medical advisor to the Coffin-Siris Syndrome Foundation. The remaining authors declare no conflict of interest.

\section{References}

1. Zawerton, A.; Yao, B.; Yeager, P.; Pippucci, T.; Haseeb, A.; Smith, J.; Wischmann, L.; Kühl, S.; Dean, J.; Pilz, D.; et al. De novo SOX4 variants cause a neurodevelopmental disease associated with mild dysmorphism. Am. J. Hum. Genet. 2019, 104, $246-259$. [CrossRef] [PubMed]

2. Bögershausen, N.; Wollnik, B. Mutations Landscapes and Phenotypic Spectrum of SWI/SNF-Related Intellectual Disability Disorders. Front. Mol. Neurosci. 2018, 11, 252. [CrossRef] [PubMed]

3. Wieczorek, D.; Bogershausen, N.; Beleggia, F.; Steiner-Haldenstatt, S.; Pohl, E.; Li, Y.; Milz, E.; Martin, M.; Thiele, H.; Altmuller, J.; et al. A comprehensive molecular study on Coffin-Siris and Nicolaides-Baraitser syndromes identifies a broad molecular and clinical spectrum converging on altered chromatin remodeling. Hum. Mol. Genet. 2013, 22, 5121-5135. [CrossRef] [PubMed]

4. Kosho, T.; Okamoto, N. Coffin-Siris Syndrome International Collaborators. Genotype-phenotype correlation of Coffin-Siris syndrome caused by mutations in SMARCB1, SMARCA4, SMARCE1, and ARID1A. Am. J. Med. Genet. C Semin. Med. Genet. 2014, 166C, 262-275. [CrossRef] [PubMed]

5. Santen, G.W.; Clayton-Smith, J.; The ARID1B-CSS Consortium. The ARID1B phenotype: What we have learned so far. Am. J. Med. Genet. C Semin. Med. Genet. 2014, 166C, 276-289. [CrossRef] [PubMed]

6. Tsurusaki, Y.; Koshimizu, E.; Ohashi, H.; Phadke, S.; Kou, I.; Shiina, M.; Suzuki, T.; Okamoto, N.; Imamura, S.; Yamashita, M.; et al. De novo SOX11 mutations cause Coffin-Siris syndrome. Nat. Commun. 2014, 5, 4011. [CrossRef] [PubMed]

7. Hempel, A.; Pagnamenta, A.T.; Blyth, M.; Mansour, S.; Mcconnell, V.; Kou, I.; Ikegawa, S.; Tsurusaki, Y.; Matsumoto, N.; Lo-Castro, A.; et al. Deletions and de novo mutations of SOX11 are associated with a neurodevelopmental disorder with features of Coffin-Siris syndrome. J. Med. Genet. 2016, 53, 152-162. [CrossRef] [PubMed]

8. Vergano, S.; Santen, G.; Wieczorek, D.; Wollnik, B.; Matsumoto, N.; Deardorff, M. Coffin siris syndrome. In Gene Reviews; University of Washington: Seattle, WA, USA, 2018. 
9. Vasileiou, G.; Vergarajauregui, S.; Endele, S.; Popp, B.; Büttner, C.; Ekici, A.B.; Gerard, M.; Bramswig, N.C.; Albrecht, B.; ClaytonSmith, J.; et al. Mutations in the BAF-complex subunit DPF2 are associated with Coffin-Siris syndrome. Am. J. Hum. Genet. 2018, 102, 468-479. [CrossRef] [PubMed]

10. Jung, E.; Moffat, J.J.; Liu, J.; Dravid, S.M.; Gurumurthy, C.; Kim, W. Arid1b haploinsufficiency disrupts cortical interneuron development and mouse behavior. Nat. Neurosci. 2017, 20, 1694-1707. [CrossRef] [PubMed] 